\title{
Minimally invasive off-pump implantation of HeartMate 3 left ventricular assist device
}

\author{
Diyar Saeed, MD, PhD, ${ }^{\mathrm{a}}$ Stephan Sixt, MD, $\mathrm{PhD},{ }^{\mathrm{b}}$ Alexander Albert, $\mathrm{MD}, \mathrm{PhD},{ }^{\mathrm{a}}$ and \\ Artur Lichtenberg, MD, $\mathrm{PhD}^{\mathrm{a}}$, Düsseldorf, Germany
}

From the ${ }^{\mathrm{a}}$ Department of Cardiovascular Surgery and ${ }^{\mathrm{b}}$ Clinic for Anesthesiology, University Hospital of Düsseldorf, Heinrich-Heine University, Düsseldorf, Germany.

Disclosures: Authors have nothing to disclose with regard to commercial support.

Received for publication March 14, 2016; revisions received May 24, 2016; accepted for publication June 26, 2016; available ahead of print Aug 28, 2016.

Address for reprints: Diyar Saeed, MD, PhD, Department of Cardiovascular Surgery, University Hospital of Düsseldorf, Heinrich-Heine University Moorenstraße 5, 40225 Düsseldorf, Germany (E-mail: diyar.saeed@ med.uni-duesseldorf.de).

J Thorac Cardiovasc Surg 2016;152:1446-7

$0022-5223 / \$ 36.00$

Copyright (c) 2016 by The American Association for Thoracic Surgery

http://dx.doi.org/10.1016/j.jtcvs.2016.06.062

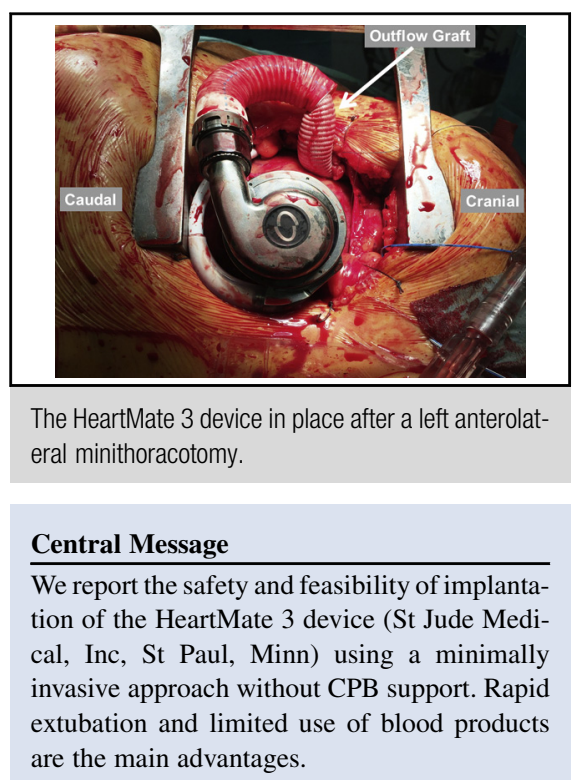

See Editorial Commentary page 1448.
The HeartMate 3 left ventricular assist device (LVAD) (St Jude Medical, Inc, St Paul, Minn) is a new continuous-flow pump that has been introduced recently for clinical use after completion of clinical trials. ${ }^{1}$ The HeartMate 3 device uses a fully magnetically levitated (Full MagLev) rotor with large blood-flow paths to minimize shear forces, which is expected to reduce detrimental effects on blood components. The inflow cannula is attached to the pump and inserted into the left ventricle, and the pump is positioned in the pericardial space. These features allow less-invasive pump implantation without the use of cardiopulmonary bypass (CPB).

The feasibility of off-pump, less-invasive implantation of the HeartWare HVAD (HeartWare International, Inc, Framingham, Mass) has been demonstrated. ${ }^{2-5}$ Advantages of offpump LVAD implantation include rapid extubation, faster rehabilitation, and lower number of blood products. ${ }^{2-5} \mathrm{We}$ describe the technique that was used for the first 4 minimally invasive off-pump implantations of the HeartMate 3 LVAD.

\section{TECHNIQUE}

The left side of the patient was slightly elevated using a pillow. The CPB was primed in every patient, and a guidewire was inserted percutaneously into the femoral vein for use in emergency situations. A moderate dose of inotropic agents (milrinone and epinephrine) and nitric oxide inhalation were initiated and continued throughout the procedure. Through a J-shaped incision at the third intercostal space, an upper hemisternotomy was performed similar to the procedure used for a minimally invasive aortic valve replacement. An anterolateral minithoracotomy was performed through the fifth or sixth intercostal space on the basis of prior echocardiography assessment of the exact position of the left ventricular apex. Video 1 shows different aspects of the procedure. Several pericardial plication sutures were placed to allow exposure of the left ventricular apex. At this stage of the procedure, excessive cardiac manipulation was avoided to prevent arrhythmias. Transesophageal echocardiography (TEE) was performed to assess the proper location of the inflow cannula before the attachment of the apical sewing ring. The sewing ring was then attached to the epicardium at the apex with 8 to 10 felt pledgeted sutures. Prolene suture (Ethicon, Somerville, NJ) was placed in a running fashion along the cuff of the sewing ring to aid in securing the device. Heparin was given to achieve an activated clotting time of more than 400 seconds. A temporary pacemaker wire was attached to the left ventricle. Rapid pacing at 180 beats/min was initiated. The apex was incised within the sewing ring using a number 11 blade. Because the currently available coring knife from the HeartMate 3 device does not allow device implantation without $\mathrm{CPB}$, a HeartWare coring knife was used and the coring was performed. After removal of the coring knife, the inflow from the pump was inserted into the ventricle and fixed using a fixing tool (Figure 1). Deairing was performed immediately after pump insertion by allowing blood to fill the outflow graft before it was crossclamped. Proper positioning of the inflow cannula was assessed using TEE 


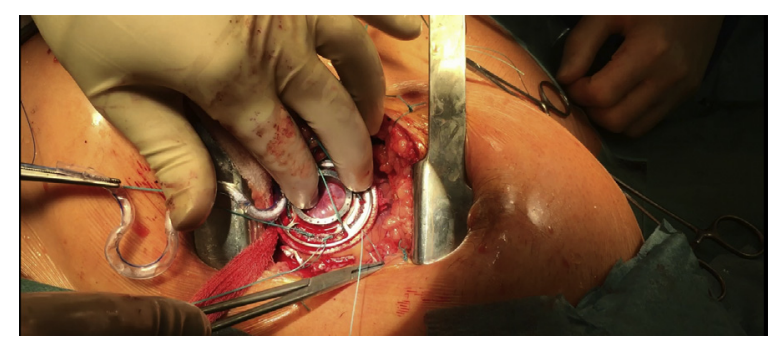

VIDEO 1. Step-by-step demonstration of minimally invasive off-pump HeartMate III (St Jude Medical, Inc, St Paul, Minn) implantation. Video available at http://www.jtcvsonline.org/article/S0022-5223(16)30879-0/addons.

(Figure 2). The driveline was brought out of the thoracotomy incision and tunneled. The outflow graft was then tunneled through the pericardium to the ascending aorta. An important point is not to attach the strain relief of the outflow graft before pulling the graft through the pericardium because the metal ring of the strain relief may hinder uncomplicated pulling without increasing the size of the thoracotomy incision. The aorta was partially clamped, and an end-to-side anastomosis was performed. The pump was turned on, and further deairing was performed through needles inserted in the outflow graft and ascending aorta.

Four patients were supported with the HeartMate 3 device using the described technique: a 63-year-old man with dilated cardiomyopathy, a 70-year-old woman with ischemic cardiomyopathy, a 55-year-old man with dilated cardiomyopathy, and a 57-year-old man with ischemic cardiomyopathy. The average preoperative INTERMACS profile was $3.5 \pm 0.6$. All patients were extubated early after the procedure and have been free of serious procedure-related adverse events.

\section{COMMENT}

These 4 cases demonstrate the safety and feasibility of implantation of the HeartMate 3 device using a minimally invasive approach without CPB support. To our knowledge, these are the first 4 patients who have been supported with the HeartMate 3 device in an off-pump technique.

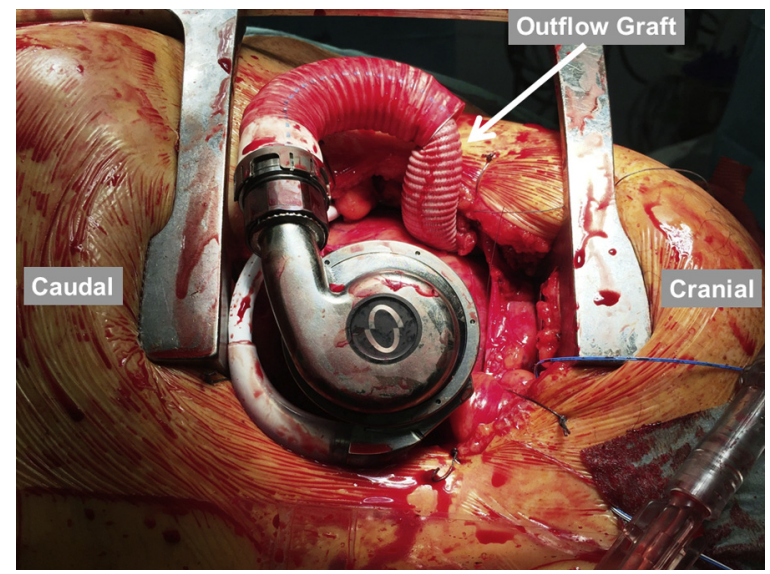

FIGURE 1. The HeartMate 3 device (St Jude Medical, Inc, St Paul, Minn) in place after a left anterolateral minithoracotomy.

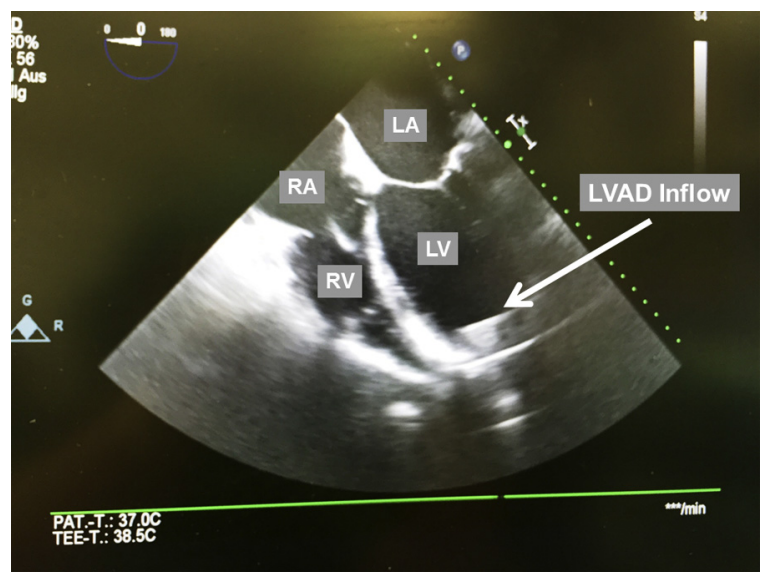

FIGURE 2. TEE 4-chamber view showing the correct positioning of the HeartMate 3 pump after implantation. $L A$, Left atrium; $R A$, right atrium; $L V$, left ventricle; $R V$, right ventricle.

Because of the lack of direct visualization of the left ventricle, extreme care must be given to rule out thrombus within the left ventricle using TEE (or 3-dimensional TEE). The most critical time of this procedure is when the apical coring is performed. Some surgeons have described the use of adenosine or coring on the beating heart (used for patients 3 and 4) for off-pump LVAD implantation, but these are anecdotal experiences and the optimal technique is yet to be determined. ${ }^{2,4}$

\section{CONCLUSIONS}

Minimally invasive off-pump implantation of the HeartMate 3 device seems to be feasible and safe. However, the currently available surgical tools allow minimally invasive implantation but only with CPB. Therefore, at this stage, we recommend using the HeartWare coring knife at the time of coring, which facilitates the off-pump implantation. Further studies are needed to confirm the advantages of offpump LVAD implantation compared with conventional implantation procedures using $\mathrm{CPB}$.

The authors thank Dr Alexander Assmann for assistance during preparation of the video.

\section{References}

1. Netuka I, Sood P, Pya Y, Zimpfer D, Krabatsch T, Garbade J, et al. Fully magnetically levitated left ventricular assist system for treating advanced HF: a multicenter study. J Am Coll Cardiol. 2015;66:2579-89.

2. Bottio T, Bejko J, Gallo M, Bortolussi G, Gerosa G. Less invasive implantation of HeartWare left ventricular assist device [serial online]. Multimed Man Cardiothorac Surg. July 11, 2014; http://dx.doi.org/10.1093/mmcts/mmu008.

3. Khalpey Z, Smith R, Echeverria A, le Tran P, Kazui T. A novel minimally invasive off-pump biventricular assist device insertion technique. J Thorac Cardiovasc Surg. 2016;151:e5-7.

4. Strueber M, Meyer AL, Feussner M, Ender J, Correia JC, Mohr FW. A minimally invasive off-pump implantation technique for continuous-flow left ventricular assist devices: early experience. J Heart Lung Transplant. 2014;33:851-6.

5. Wagner CE, Bick JS, Kennedy J, Haglund N, Danter M, Davis ME, et al. Minimally invasive thoracic left ventricular assist device implantation; case series demonstrating an integrated multidisciplinary strategy. J Cardiothorac Vasc Anesth. 2015;29:271-4. 